\title{
Experimental long term diagenetic alteration of aragonitic biocarbonates.
}

\author{
PABLO FORJANES ${ }^{1}$, MARÍA SIMONET-RODA ${ }^{2}$, \\ MARTINA GREINER ${ }^{2}$, ERIKA GRIESSHABER ${ }^{2}$, JOSÉ \\ MANUEL ASTILLEROS ${ }^{1,3}$, WOLFGANG SCHMAHL ${ }^{2}$ AND \\ LURDES FERNÁNDEZ-DÍAZ ${ }^{1,3}$ \\ ${ }^{1}$ Universidad Complutense de Madrid \\ ${ }^{2}$ LMU München \\ ${ }^{3}$ Instituto de Geociencias IGEO (CSIC-UCM) \\ Presenting Author: pforjane@ucm.es
}

Biocarbonates are archives that contain valuable geochemical information for paleoenvironmental studies and reconstruction of past climate dynamics. However, this information can be lost along with other mineralogical and textural data due to the diagenetic alteration processes that most biocarbonates undergo during burial. Determining the intrinsic properties of carbonate skeletons that influence to what extent original geochemical features can be overprinted by diagenesis is key for safely using carbonate biominerals as paleoenvironmental proxies.

Recent works [1,2] have shown how the hydrothermal interaction $\left(175^{\circ} \mathrm{C}\right)$ of aragonitic biominerals with diagenetic-like burial fluids results in the replacement of their microstructures by inorganic calcite blocky crystals through a dissolutioncrystallization reaction that involves several steps. Aiming to better understand these steps, we experimentally studied the long term alteration (4 and 6 months long at $80^{\circ} \mathrm{C}$ ) of several aragonitic marine skeletons with different microstructures: Arctica islandica, with unstructured aragonite; Haliotis ovina, which contain prismatic aragonite and nacre tablets, and Porites $s p$, with a skeleton consisting of blocky spherulitic and fibrous aragonite. The altered skeletons were analyzed with EBSD, SEM, AFM, XRD and TGA.

The extent and characteristics of the hydrothermal alteration strongly differs depending on the original aragonitic microstructure. Hence, while aragonite crystals from Porites $s p$. remains unaltered after 6 months interaction with burial-like fluids, even at the nanoscale, all other three aragonitic skeletons appear partially transformed. The degree of transformation is largest in the prismatic layer of Haliotis ovina, which appears partially transformed to calcite. In all cases, the destruction of the organic biopolymers and subsequent formation of microporosity are initial steps of the alteration process, which precede the growth of inorganic aragonite in the newly formed micropores. Afterwards, this aragonite is replaced by blocky calcite. Our results depict the diagenesis of aragonitic biocarbonates as a complex multi-step process whose development is strongly influenced by physicochemical, mineralogical, and microstructural and -textural parameters.

[1] Casella et al. (2017). Biogeosciences. 14. 1461-1492

[2] Casella et al. (2018). Biogeosciences. 15. 7451-7484 